\title{
An Investigational Study of Energy Conservation Techniques in Hierarchical Routing Protocols in Wireless Sensor Network
}

\author{
Hemawathi.P \\ Research Scholar, \\ Jain University, Bangalore, India
}

\author{
T G Basavaraju, Ph.D \\ Dept of CS\&E \\ Govt. SKSJTI \\ Bangalore, India
}

\begin{abstract}
In the advent of wireless networking, wireless sensor network (WSN) has been a constant target of research due to its potential data aggregation techniques in hostile environment. Even after crossing more than a decade, wireless sensor network is still more under research and development and less on commercial deployment when it comes to large scale wireless environment. Although, there are various issues exists in WSN that ranges from quality of service to security policies, it was frequently seen that root cause of majority of the issues originates from the energy that backs up the sensor motes to transmit the data to base station. The past research work has witness massive volumes of algorithms using various sophisticated technologies in order to mitigate the issues of energy problems in sensor motes, however, till date none of the prior studies has yet been standardized and hence the issues of unwanted power depletion still persist because of numerous unsolved factors. This paper is an attempt to study only the prominent techniques that has been introduced in the past for energy efficiency exclusively for hierarchical routing protocols. A brief review of some prior Swarm Intelligence (SI) techniques is also given a special focus for the similar purpose in this paper.
\end{abstract}

\section{Keywords}

Wireless Sensor Network, Hierarchical Routing Protocol, LEACH, battery, power depletion, Swarm Intelligence

\section{INTRODUCTION}

The area of wireless sensor network has exhibits its potential features in the communication purpose. The wireless sensor network comprises of sensor nodes deployed in the area which are required to be monitored for certain activity of human interest [1]. The sensor nodes are small miniature electronic device that has the capability to sense certain physical attributes like water, heat, pressure, motion, smoke and many more attributes. These attributes are usually collected the sensor nodes using TDMA scheduling mechanism. There are various applications of wireless sensor network right from habitat monitoring to forest fire detection. The applications are either designed for small scale or for large scale area. However, the wireless sensor network is also found with certain flaws that has attracted the attention of the research community. A sensor node is usually smaller in size with less computational and storage capabilities. Hence, when the research work is carried out, such issues are usually not visualized in correct sense by the developers or the researchers for which reason, the evolved technique or the algorithm could not be benchmarked properly. It was also explored that energy is one of the biggest impediment in superlative performance of the routing protocols in wireless sensor network [2][3]. If the energy is depleted, it gives rise to unstabilized links that finally yields to degradation of the performance of either data aggregation process or network lifetime enhancement process. It is quite evident that right from node deployment phase to cluster formation phase, the network needs to be designed in such a way that it really optimize each and every constraints of the system for yielding better results. Also, it was seen from the literature that majority of the studies in the energy efficient routing is based on on-demand routing protocols as such routing protocols are highly capable of conserving energy considering the existing constraints of the sensor node. Hence, a better version of algorithm is required that can ensure cumulative network lifetime with computationa capabilities. In this paper, we are discussing about an open issues in wireless sensor network i.e. energy efficiency of hierarchical routing protocols. Although there are many other categories of routing protocols, but we restrict our discussion in hierarchical routing techniques as it was seen that majority of the prior studies on energy efficiencies are designed on the top of hierarchical routing protocol. We are curious to understand what the significant and standard energy efficient routing protocols are and what its limitations are. Hence, to answer this question, this paper will collect only the standard papers, where some significant contributions were witnessed. We have also collected the most recent studies being undertaken to ascertain this fact and to explore the research gap in this field. Finally, we discuss about the most recent trend of adopting swarm based technique for optimizing the routing performance and thereby enhancing the cumulative network lifetime of the wireless sensor network. This paper discusses about various energy efficient techniques on hierarchical routing protocols along with their classification and finally the paper also discusses about swarm intelligence techniques for energy efficient routing in WSN. Section-2 discusses about the various design challenges for routing protocols in wireless sensor networks followed by discussion on existing hierarchical routing protocols in Section 3. Section 3 also discusses about the pros and cons of some of the recent studies in the similar issues. Section 4 discusses about the techniques adopted in swarm intelligence for the energy efficiency and optimization purpose followed by conclusion in Section 5

\section{DESIGN CHALLENGES FOR WSNS ROUTING PROTOCOLS}

The design aspects of wireless sensor network have always poses a challenges and impediments towards various research works carried out in routing protocols. The wireless sensor network is quite different in design principles from conventional wireless adhoc networks. Different from conventional adhoc nature, wireless sensor network uses multicast communication 
pattern using tree concepts [3]. Due to smaller size of the sensor nodes with less computational capabilities, it is very difficult to formulate and exercise a new routing algorithm in the tiny sensor mote [4]. Therefore, the design challenges of wireless sensor network can be briefly discussed as below:

- Self-Organization: For a better communication, a robust routing is required that calls for better node and network lifetime with potential sustainance capabilities. Therefore, a breakage in one link actually interrupts the complete network damaging the communication system. Hence, Autonomicity or adhoc nature of routing is highly essential in wireless sensor network that is highly effective on resource constraint node [5].

- Memory: Usually, the sensor mote is very small and hence storage or memory is highly restricted. Because of this, a high end algorithm finds quite difficult and sometime impossible to run. Hence, this is one of the biggest 'constraint' where one hand, there is solution and on other hand there is hardware constraint of memory posing as essential design issues in wireless sensor network.

- Scalability: The applications of wireless sensor network ranges from low scale to large scale deployment. Sometimes in mission critical applications, the nodes find it real difficult task to perform communication using their routing protocols in the presence of channel noise, channel fading, interference etc. Hence, when some of the nodes started showing performance degradation, it affects the cumulative performance of the wireless sensor network. Hence, scalability will mean that till what extent wireless sensor network's performance is independent of the numbers of nodes. It will exhibit the optimal number of sensor nodes that can effectively carry out the routing posing it another design issues in wireless sensor network difficult to address owing to environmental impediments.

- Architecture: Although the theory and literatures of wireless sensor network speaks about various types of architectures and topologies meant for usage in various applications, but few of them are really applicable and found less efficient in real time environment. Hence, one of the design impediments of wireless sensor network is to have an efficient architecture that matches the traffic requirements of the real time environment.

- In-Network Data Aggregation: At the time of data aggregation, it is quite possible that cluster head may accumulate redundant data. It is also possible that different clusters too can posses same redundant data, that reduces the performance of the routing in wireless sensor network by provoking maximized number of re-transmission attempts. This phenomenon also leads to unwanted energy drainage. Hence, conventional theory of data aggregation from member to cluster node is obviously witnessed with flaws that encapsulates the redundant data posing a design challenges in wireless sensor network.

- Energy: Some of the studies e.g. [2] has literally exhibited that root cause of majority of the problems (like routing, packet delivery, latency, security etc) in wireless sensor network is because of unwanted and uncontrollable energy depletion. Till date, researchers are struggling with this issues, although few algorithms has been mechanism in past studies, but the robust design factors to address the energy issues is still an open issues in the area of wireless sensor network.
- Clustering: Another design aspects of the wireless sensor network is to perform an efficient mechanism of clustering. If clustering is not done properly, it leads to inappropriate selection of cluster head, which can reduce the performance of data aggregation. Some of the literatures like [6] suggest that existing clustering techniques are applicable only on conventional adhoc network and has less supportability on wireless sensor network based on its real time requirements.

\section{EXISTING HIERARCHICAL ROUTING PROTOCOLS}

Although there are various types of routing protocols that are conventionally designed for meeting the communication requirements of wireless sensor network, however, it has been noticed that majority of the energy efficiency were addressed using hierarchical routing protocols. In this types of routing, the entire focus is made on sensor nodes (sometimes called as member nodes), cluster head, and base station (also called as sink). The prime task of sensor node is to sense the physical data and forward it to its respective cluster head. The cluster head performs aggregation of data and then forwards the unique and non-redundant data to the base station. The data aggregation process continues until the nodes are depleted of its respective energy. Some of the standard hierarchical routing protocols that are meant for energy efficiencies are discussed briefly as follows,

- Low Energy Adaptive Clustering Hierarchy (LEACH): This is one of the most frequently studied routing protocols for any research work aiming at energy efficiencies. The model was introduced in 2000 and has considered designing an effective radio and energy model, which is highly adopted even in current studies. LEACH [7] algorithm considers homogenous wireless sensor network where the base station is located in the center of the simulation area and surrounded by multiple clusters. The selection of the cluster head is always done depending on the highest residual energy. The cluster head uses TDMA scheduling to aggregate the physical data from the member nodes on one cluster. The entire operation of the LEACH is carried out using set up phase and steady phase. The energy depletion is controlled by reducing the cost of communication between the member node and cluster head using sleep scheduling algorithms. Hence, lifetime of the network is maximized in LEACH.

- Hybrid, Energy-Efficient Distributed Clustering (HEED): It is an enhanced version of LEACH routing protocols that considers residual power as well as node density as a selection criteria of clusterhead [8], [9]. The outcome of the HEED routing protocol is found with better energy efficiencies even compared to LEACH with better reduction in overhead and maximizing the network lifetime.

- Power-Efficient Gathering in Sensor Information Systems (PEGASIS): Just like HEED, it is also an enhanced version of LEACH routing protocol where the outcome shows that energy efficiencies capabilities are doubled up even compared to conventional LEACH [10]. The aggregated data are not forwarded to base station directly, inspite, the aggregated data are transmitted through a communication channel to the neighbor networks, which is finally forwarded to the base station. The phenomenon of cluster formation is evaded in PEGASIS and considers that all the sensor nodes have prior information about the wireless sensor network using greedy algorithm 
Table 1 Summary of Most recent studies in energy efficient routing techniques

\begin{tabular}{|c|c|c|c|}
\hline Authors & Problem Focused & Techniques Applied & Inference \\
\hline $\begin{array}{l}\mathrm{Xu} \text { et al.[14]- } \\
2014\end{array}$ & $\begin{array}{l}\text { Energy efficiency in } \\
\text { routing }\end{array}$ & $\begin{array}{l}\text { Density-based } \quad \text { Energy-efficient } \\
\text { Clustering Heterogeneous Algorithm }\end{array}$ & $\begin{array}{l}\text {-The } \mathrm{CH} \text { selection procedure is same as } \\
\text { conventional }\end{array}$ \\
\hline $\begin{array}{l}\text { Lee et al.-[15]- } \\
2014\end{array}$ & $\begin{array}{l}\text { Energy efficiency in } \\
\text { routing }\end{array}$ & $\begin{array}{l}\text { Energy-Efficient QoS-aware Routing } \\
\text { Algorithm }\end{array}$ & $\begin{array}{l}\text {-No evidence of standard benchmarking } \\
\text { with significant routing protocols }\end{array}$ \\
\hline $\begin{array}{l}\text { Zytoune-[16]- } \\
2014\end{array}$ & $\begin{array}{l}\text { Energy efficiency in } \\
\text { routing }\end{array}$ & Time Based Clustering Technique & $\begin{array}{l}\text { No evidence of standard benchmarking } \\
\text { with significant routing protocols }\end{array}$ \\
\hline $\begin{array}{l}\text { Poostfroushan } \\
\text { et al. -[17]- } \\
2014\end{array}$ & $\begin{array}{l}\text { Energy efficiency in } \\
\text { routing }\end{array}$ & Particle Swarm Optimization Algorithm & $\begin{array}{l}\text {-No evidence of standard benchmarking } \\
\text { with significant routing protocols } \\
\text {-Energy variation is not discussed }\end{array}$ \\
\hline $\begin{array}{l}\text { Haider et al.- } \\
{[18]-2014}\end{array}$ & $\begin{array}{l}\text { Energy efficiency in } \\
\text { routing }\end{array}$ & $\begin{array}{l}\text {-REECH-ME: }{ }^{2} \text { Regional } \\
\text { Efficient Cluster Heads based on } \\
\text { Maximum Energy Routing Protocol } \\
\text { with Sink Mobility }\end{array}$ & $\begin{array}{l}\text {-Better network lifetime achieved. } \\
\text {--Energy variation is not discussed }\end{array}$ \\
\hline $\begin{array}{l}\text { Zhang et al.- } \\
{[19]-2014}\end{array}$ & $\begin{array}{l}\text { Energy efficiency in } \\
\text { routing }\end{array}$ & $\begin{array}{l}\text {-distributed energy-efficient unequal } \\
\text { clustering routing protocol }\end{array}$ & $\begin{array}{l}\text { - better balance energy consumption, } \\
\text { improve energy efficiency and then } \\
\text { prolong the network lifetime } \\
\text {-Algorithm convergence behaviour not } \\
\text { discussed } \\
\text {-Multiple hop not addressed }\end{array}$ \\
\hline $\begin{array}{l}\text { Shu \& Wang- } \\
{[20]-2013}\end{array}$ & $\begin{array}{l}\text { Energy efficiency in } \\
\text { routing }\end{array}$ & $\begin{array}{l}\text { An Optimized Multi-hop Routing } \\
\text { Algorithm Based on Clonal Selection }\end{array}$ & $\begin{array}{l}\text {-Better performance compared to } \\
\text { PEGASIS } \\
\text {-No discussion on comparison with } \\
\text { LEACH } \\
\text {-possible control overheads are not } \\
\text { discussed } \\
\text {-Result achieved from less simulation } \\
\text { rounds }\end{array}$ \\
\hline $\begin{array}{lrr}\text { Deng et } & \text { al.- } \\
{[21]-2013} & \end{array}$ & $\begin{array}{l}\text { Prolong the lifetime } \\
\text { of the network. }\end{array}$ & $\begin{array}{lll}\text { Balancing } & \text { Energy } & \text { Consumption } \\
\text { LEACH (BEC-LEACH) protocol }\end{array}$ & $\begin{array}{l}\text {-Result achieved from less simulation } \\
\text { rounds } \\
\text {-Only } 5 \text { clusters are evaluated. } \\
\text {-Energy variance is not discussed. }\end{array}$ \\
\hline Alia-[22]-2013 & $\begin{array}{ll}\text { Extending } & \text { Wireless } \\
\text { Sensor } & \text { Network } \\
\text { Lifetime } & \end{array}$ & Harmony Search Algorithm & $\begin{array}{l}\text {-Energy variance is not discussed. } \\
\text {-Result achieved from less simulation } \\
\text { rounds } \\
\text {-Overheads not discussed }\end{array}$ \\
\hline $\begin{array}{l}\text { John \& } \\
\text { Ramson-[23]- } \\
2013\end{array}$ & $\begin{array}{l}\text { Efficient } \\
\text { collection }\end{array}$ & Energy-Aware Duty Cycle Scheduling & $\begin{array}{l}\text {-Not compared with LEACH } \\
\text {-doesn't address any optimization. }\end{array}$ \\
\hline $\begin{array}{l}\text { Zhao \& Yang- } \\
{[24]-2014}\end{array}$ & prolong the lifetime & LEACH-A & - performs better than the LEACH \\
\hline $\begin{array}{l}\text { Kim et al.-[25]- } \\
2014\end{array}$ & Optimization & $\begin{array}{l}\text { IC-ACO: Inter cluster Ant colony } \\
\text { Optimization Algorithm }\end{array}$ & Selection of $\mathrm{CH}$ is just like LEACH \\
\hline $\begin{array}{l}\text { Zungeru et al.- } \\
{[26][2013]}\end{array}$ & $\begin{array}{l}\text { Optimization of } \\
\text { swarm approaches }\end{array}$ & $\begin{array}{l}\text {-Comparative study of the routing } \\
\text { performance of swarm based techniques }\end{array}$ & $\begin{array}{l}\text { Energy aware routing objectives increases } \\
\text { the network lifetime }\end{array}$ \\
\hline
\end{tabular}

- Threshold Sensitive Energy Efficient Sensor Network Protocol (TEEN): This is another hierarchical routing protocol mainly designed for mission critical requirements in any applications in reactive networks [11]. The aggregated data from the cluster head is forwarded to the upper level of clusterhead and this phenomenon is continued for all the clusters until the forwarded data reaches base station. TEEN maintains energy conservation by occasionally using threshold base approach forwarding the unique data (although the member node spontaneously generates the data to the cluster head).

- Adaptive Periodic Threshold Sensitive Energy Efficient Sensor Network Protocol (APTEEN): It is an enhanced version of conventional TEEN protocol primarily targeting at periodic collection of physically sensed data from member node and promptly responding in mission / time critical applications [12]. The selection of the clusterhead is almost like that of LEACH protocol. APTEEN also used enhanced TDMA scheduling thereby allocating a precise slot for transmission for preventing data redundancies.

- Clustered Aggregation Technique (CAG): Just like TEEN, CAG [13] is primarily designed for the reactive network. All the sensor nodes that sense equivalent physical data are formulated as one cluster and perform operation to check redundancies of data by filtering out unwanted elements thereby reducing the response time. CAG also addresses better storage efficiency and efficient cost of communication.

Limitations of Standard Hierarchical Routing Protocols: Although there are standard hierarchical routing protocols in wireless sensor network, but it has been seen that majority of them are not without flaws. For an example, the most frequently studied LEACH routing protocol selects its clusterhead arbitrarily that doesn't ensure the effective distribution of 
clusterhead. The biggest flaw in technical consideration in LEACH is that it still considers a node with lowest residual energy as clusterhead resulting in faster rate of power depletion. Moreover, LEACH doesn't address the multi-hop communication requirements in large scale wireless sensor network [27]. Similarly, the HEED protocol is also not much reliable as it prioritizes remnant energy and then topological attributes like node density, relative distances among the clusters etc. It is because all the nodes do posses same initial energy in start up in homogenous network thereby do not ensure better network lifetime [28]. In PEGASIS, there is a massive need of adjustment of dynamic topology as the energy condition of the neighbor clusters are required to be known for routing purpose. This task requires lot of significant network overhead [10]. In TEEN, which is basically dependent on threshold based technique; the sensor nodes may possibly not perform communication if the threshold is not reached. Problem starts appearing when the node starts depleting energy in TEEN [11]. One of the limitations of CAG protocol is that it doesn't support proactive as well as reactive data collection based on real-time requirements of wireless sensor network [29.] Although there are some of the significant research attempts in past, it can be seen that majority of the standard hierarchical routing protocols are found with limitations that act as an impediment towards maximizing the network lifetime of wireless sensor network. The next section discusses about the upcoming trend of using swarm intelligence for the purpose of optimizing the routing performance in wireless sensor network.

\section{APPROACH IN SI}

Very recently, swarm intelligence has also drawn an attention from the research community for its potential capabilities in optimizing the routing performance in wireless sensor network and thereby addressing energy efficiencies. Swarm intelligence deals with design of an algorithm for a specific problem based on social or cognitive behaviour of any living organism [30], [31], [32]. Various applications designed and derived from the evolutionary theories of swarm intelligence are mainly particle swarm optimization (PSO) $[35,36]$ and ant colony optimization (ACO) [33] [34]. This section will briefly highlight the contribution of various researchers using swarm intelligence for addressing routing issues in wireless sensor network.

The first prototype of swarm intelligence was done in 1990 on wired network by significant researchers e.g. Schoonderwoerd et al. [37] and Di Caro and Dorigo [38] [39]. The authors have used cognitive behaviour of ant and introduced Ant Based Control and AntNet algorithm respectively motivated by the essential principle of ant colony optimization. However, such preliminary studies were also contradicted by various researchers, as evident in literature [40], as absence of standard analysis and supportability findings that makes the prior approaches almost unreliable for implementation purpose. The literature [41] has also attempted to motivate the readers about the need of swarm intelligence in enhancing the routing performance keeping future applications in mind. Different significant approaches of the ant colony optimization for the routing purpose are discussed by Sim and Sun [42]. The authors have discussed that by using this technique load balancing issues can be reduced significantly.

An elaborated discussion on evolutionary techniques like genetic algorithm, ant colony optimization, particle swarm optimization and various other swarm inspired algorithms are investigated by the Ren and Meng [43]. The authors discussed the possible benefits of routing by adopting such techniques in wireless sensor network. In-depth investigations of routing algorithm designed exclusively by genetic algorithm as well as other ant based techniques are discussed in the study of Iyenger et al. [44]. However, the discussion in more focused on adhoc networks and less on wireless sensor networks. Various attempts of surveying techniques of ant colony optimization for enhancing quality of services in wireless sensor network was also witnessed in the study of Ducatelle et al. [45]. The study has laid a strong foundation of enhancing performance of wireless sensor network using swarm based techniques.

Sausen et al. [46] investigated about the techniques of energy efficient routing in wireless sensor network using dual tactics. The author has introduced a technique that performs scheduled switching system for managing energy dynamically. The study is more focused on addressing the sleep to active and vice-versa for conservation of energy in wireless sensor network. The second tactics renders a group of node in active state while making the other nodes in inactive state thereby saving energy. Use of multi-objective evolutionary technique was witnessed in the study of Marcelloni and Vecchio [47]. Although there are abundant set of publications in addressing energy efficiencies in routing protocols in wireless sensor network, where swarm based technique has played a crucial foundation in optimization principle, but very few research publications are found to address energy efficient routing protocols exclusively considering Hierarchical routing type. Hence, this fact will act as research gap as well as open issues which are anticipated to be addressed in near future.

\section{CONCLUSION}

Although there has been lots of attempts in addressing the energy efficient routing in wireless sensor network, but very few works are seemed to be benchmarked. It was also seen that frequently considered algorithm like $\mathrm{LEACH}$, which various academician as well as various research scholar considers to be benchmarked is also accompanied by various flaws. It was seen that majority of the research work is symptomatic, which will mean that if the researcher is focusing on routing issues, he misses out other associated aspects that are also connected with routing. In short the selection of performance parameters are found not wise enough, as while proposing a new routing protocol, the literatures didn't found any description of reliability, optimization as well as security although it may have good packet delivery ratio, latency, energy etc. Hence, it is very important to visualize the performance parameters in order to justify how much efficient the routing protocols are in addressing energy conservation in wireless sensor network. This paper has discussed very briefly about the evolution of hierarchical routing protocols. The paper starts discussing about the possible design challenges which are yet to be address in the viewpoint of energy efficiency routing principles. Various hierarchical routing protocols like LEACH, TEEN, APTEEN, PEGASIS, and CAG etc are discussed briefly along with their explored limitations. Various approaches of swarm based approaches are briefly discussed to explore the research gap and open issues. The direction of our future work will towards formulating an energy efficient hierarchical routing algorithm that addresses the issues discussed in this paper.

\section{REFERENCES}

[1] Dargie, W, Poellabauer, C. 2010. Fundamentals of Wireless Sensor Networks: Theory and Practice, John Wiley \& Sons, Technology \& Engineering - 336 pages

[2] Ma, C. 2007. Battery-aware and Energy-efficient Algorithms for Wireless Networks, Doctorial Thesis of Stony Brooks University 
[3] Raghavendra, C, Krishna, K, Znati, T. 2004. Wireless Sensor Networks, Springer-Verlag.

[4] Akyildiz, IF, Su, W., Sankarasubramaniam, Y., Cayirci, E. 2002. A survey on sensor networks, IEEE Communications Magazine, vol. 40 (8), pp.102-114

[5] Kephart, J., Chess, D. 2003. The vision of autonomic computing, IEEE Computer Magazine, vol.36 (1), pp. 4150 .

[6] Zheng, J., Jamalipour, A .2009.Wireless Sensor Networks: A Networking Perspective., a book published by A John \& Sons, Inc, and IEEE

[7] Heinzelman, W.R., Chandrakasan, A., Balakrishnan, H.2000. Energy- efficient Communication Protocol for Wireless Microsensor Networks, in IEEE Computer Society Proceedings of the Thirty Third Hawaii International Conference on System Sciences (HICSS '00), Washington, DC, USA, 2000, vol. 8, pp. 8020

[8] Younis, O., Fahmy, S. 2004.Heed: A Hybrid, energy, Distributred Clustering Approach for Ad-hoc Networks:, IEEE Transactions on Mobile Computing Issues in Wireless Networks and Mobile Computing,vol 3,no. 4, pp.366-369

[9] Younis, O., Fahmy, S.2002. Distributed Clustering in Adhoc sensor Networks:A Hybrid Energy - efficient Approach, International Journal of Computer Science.

[10] Lindsey, S., Raghavendra, C.S. 2002. PEGASIS: Powerefficient Gathering in Sensor Information System", Proceedings IEEE Aerospace Conference, Big Sky, MT, vol. 3, pp. 1125-1130.

[11] Manjeshwar, A., Agarwal, D.P.2001. TEEN : A Protocol for Enhanced Efficiency in Wireless Sensor Networks, in the Proceedings of the 1 st International Workshop on Parallel and Distributed Computing Issues in Wireless Networks and Mobile Computing, San Francisco, CA

[12] Manjeshwar, A., Agarwal, D.P.2001. APTEEN: A Hybrid Protocol for Efficient Routing and Comprehensive Information Retrieval in Wireless in Wireless Sensor Networks,in the Proceedings of the 2nd International Workshop of Parallel and Distributed Computing Issues in Wireless Networks and Mobile Computing, San Francisco CA

[13] Yoon S., Shahabi C.2005. Exploiting Spatial Correlation Towards an Energy Efficient Clustered Aggregation Techique (CAG), IEEE Conference on Communications

[14] Xu, Z., Yin, Y., Wang, J., Kim, J-Uk.2014. A Densitybased Energy-efficient Clustering Heterogeneous Algorithm for Wireless Sensor Networks, International Journal of Control and Automation, vol.7, no.2, pp.175-188

[15] Lee, S-K., Koh, J-G., Jung, C-R.2014. An Energy-Efficient QoS-aware Routing Algorithm for Wireless Multimedia Sensor Networks, International Journal of Multimedia and Ubiquitous Engineering, vol.9, No.2 (2014), pp.245-252

[16] Zytoune, O., Aboutajdine, D.2014. A Low Energy Time Based Clustering Technique for Routing in Wireless Sensor Networks, American Journal of Sensor Technology, vol. 2, no. 1, pp.1-6

[17] Poostfroushan, S., Sarram, M.A., Sheikhpour, Razieh. 2014. Energy Efficient Backbone Formation Using Particle Swarm Optimization Algorithm in Wireless Sensor
Networks, International Journal of Grid and Distributed Computing, vol.7, no.1, pp.123-134

[18] Haider, A., Sandhu, M. M., Amjad, N.2014. REECH-ME: Regional Energy Efficient Cluster Heads based on Maximum Energy Routing Protocol with Sink Mobility in WSNs, Journal of Basic and Applied Scientific Research, vol.4(1),pp.200-216

[19] Zhang, C., Liu, Fangai., WU, Nan.2014. A Distributed Energy-e_cient Unequal Clustering Routing Protocol for Wireless Sensor Networks, Journal of Computational Information Systems, vol. 10: 6, pp. 2369-2376

[20] Shu, W., Wang,J.2013. An Optimized Multi-hop Routing Algorithm Based on Clonal Selection Strategy for Energyefficient Management in Wireless Sensor Networks, Sensors \& Transducers, vol. 22, pp. 8-14

[21] Deng, H., Yang,C., Sun,Y.2013. A Novel Algorithm for Optimized Cluster Head Selection, Science Journal of Electrical \& Electronic Engineering

[22] Moh'd A- O., Al-A ,Alaa.2013. Extending Wireless Sensor Network Lifetime by Relocating of Base Station using Harmony Search Algorithm, Wireless Sensors and Cellular Systems

[23] John,J.T., Ramson, S. R. J.2013. Energy-Aware Duty Cycle Scheduling for Efficient Data Collection in Wireless Sensor Networks, International Journal of Advanced Research in Computer Engineering \& Technology (IJARCET), vol.2, Issue. 2

[24] Zhao, J., Y. Lirong. 2014.LEACH-A: An Adaptive Method for Improving LEACH Protocol, Sensors \& Transducers, vol. 162 , Issue. 1, pp. 136-140

[25] Kim, J-Y., Sharma, T., Kumar, B., Tomar, G.S., Berry, K., Lee, W-H. 2014. IC-ACO: Inter cluster Ant colony Optimization Algorithm for Wireless Sensor Network in Dense Environment, International Journal of Distributed Sensor Network

[26] Zungeru, A.M., Yahaya, E.A. 2013.Caroline Omoanatse Alenoghena3, Performance Evaluation of Energy-aware Swarm Intelligence Based Routing Protocols for Wireless Sensor Networks Based on Different Radio Models, International Journal of Computing, Communications and Networking, Vol. 2,no.4

[27] Kaur,R., Sharma, D., Kaur, N.2013. Comparative Analysis Of Leach And Its Descendant Protocols In Wireless Sensor Network, International Journal of P2P Network Trends and Technology, vol.3,Issue-1

[28] Kour, H., Sharma, A.K. 2010. Hybrid Energy Efficient Distributed Protocol for Heterogeneous Wireless Sensor Network, International Journal of Computer Applications (0975 - 8887), vol.4, no.6

[29] Yoon, S., Shahabi, C.2007. The Clustered AGgregation (CAG) TechniqueLeveraging Spatial and Temporal Correlations in Wireless Sensor Networks, ACM Transactions on Sensor Networks, vol. 3 , no. 1

[30] Bonabeau, E., Dorigo, M., Theraulaz, G. 1999. Swarm Intelligence: From Natural to Artificial Systems, Oxford University Press, New York, USA

[31] Engelbrecht, A.2007. Computational Intelligence: An Introduction, second ed., Wiley 
[32] Kennedy, J., Eberhart, R.C., Shi, Y.2001. Swarm Intelligence, Morgan Kaufman, San Francisco, USA

[33] Dorigo, M., Stützle, T.2004. (Eds.), Ant Colony Optimization, MIT press

[34] Dorigo, M., G.A. Di.1999. The ant colony optimization metaheuristic, in: D. Corne, M. Dorigo (Eds.), New Ideas in Optimization, McGraw-Hill, pp. 11-32

[35] Bashyal, S., Kumar, G., Venayagamoorthy. 2007.Collaborative routing algorithm for wireless sensor network longevity, in: Proceedings of the IEEE, International Conference on Intelligent Sensors, Sensor Networks and Information

[36] Kennedy, J., Eberhart, R.C., Shi, Y. 2001. Swarm Intelligence, Morgan Kaufman, San Francisco, USA

[37] Schoonderwoerd, R., Holland, O.E., Bruten, J.L., Rothkrantz, L.J.M.1996. Ant-based load balancing in telecommunications networks, Adaptive Behavior, vol. 5(2), pp.169-207

[38] Caro, G.A. D.2004. Ant Colony Optimization and Its Application to Adaptive Routing in Telecommunication Networks, Ph.D. Thesis, Faculté des Sciences, Appliquées, Université Libre de Bruxelles (ULB), Brussels, Belgium

[39] Caro, G.A. D., Dorigo, M.1998. AntNet: distributed stigmergetic control for communication networks, Journal of Artificial Intelligence Research (JAIR), vol. 9,pp. 317365.

[40] Farooq, M., Caro, G.A. D.2008. Routing protocols inspired by insect societies, in: C. Blum, D. Merkle (Eds.), Swarm Intelligence, Introduction and Applications, Natural Computing Series, Springer-Verlag, pp. 101-160

[41] Wedde, H.F., Farooq, M.2006. A comprehensive survey of nature-inspired routing protocols for telecommunication networks, Journal of System Architecture,vol. 52 (8),pp. 461-484.

[42] Sim, K.M., Sun, W.H.2003. Ant colony optimization for routing and load balancing: survey and new directions, IEEE Transactions on System, Man and Cybernetics, vol. 33 (5), pp. 560-572.

[43] Ren, H., Meng, M.Q.-H. 2006. Biologically inspired approaches for wireless sensor networks, in: Proceedings of IEEE the International Conference on Mechatronics and Automation

[44] Iyengar, S.S., Wu, H.C., Balakrishnan, N., Chang, S.Y.2007. Biologically inspired cooperative routing for wireless mobile sensor networks, IEEE Systems Journal, vol. 1 (1), pp. 29-37
[45] Ducatelle, F., Caro, G.A. D., Gambardella, L. 2010.Principles and applications of swarm intelligence for adaptive routing in telecommunications networks. Swarm Intelligence, in press. doi:10.1007/s11721-010-0040-x.

[46] Sausen, P.S., Spohn, M.A., Perkusich, A. 2010. Broadcast routing in wireless sensor networks with dynamic power management and multi-coverage backbones, Information Sciences, vol. 180 (5) pp.653-663.

[47] Marcelloni, F., Vecchio, M.2010. Enabling energyefficient and lossy-aware data compression in wireless sensor networks by multi-objective evolutionary optimization, Information Sciences, vol. 180 (10),pp.19241941

\section{AUTHOR'S PROFILE}

Hemavathi $\mathbf{P}$ received B.E degree in Computer Science \& Engineering from Manipal University, Karnataka, India. M. Tech Degree in Computer Science \& Engineering from VTU, Karnataka. She is now pursuing her $\mathrm{PhD}$ degree from Jain University, Bangalore. Her research interest includes Wireless Sensor Networks especially Energy Conservation Techniques in Hierarchical Routing Protocols in Wireless Sensor Networks. She is currently working as Assistant Professor in the Department of Computer Science \& Engineering of Bangalore Institute of Technology, Bangalore, Karnataka.

Dr. T G Basavaraju is currently working as Professor and Head of Computer Science and Engineering Department at Govt SKSJ Technological Institute, Bangalore. Prof. Basavaraju holds a Ph.D. (Engg.) from Jadavpur University, Kolkata in the area of Mobile Ad hoc Networks. He obtained his Master's Degree in Computer Science and Engineering from University Visvesvaraya College of Engineering (UVCE), Bangalore University, Bangalore and secured first rank. He holds Bachelor's degree in Computer Science and Engineering from University BDT College of Engineering (UBDTCE), Kuvempu University, Davangere. He has more than 16 years of experience in Teaching and Industry. He was with Axes Technologies and Samsung Electronics Co. as a Software Engineer. He has authored and co-authored five text books in the area of Computer Networking. One of his co-authored text book on" Mobile Wireless Ad hoc Networks: Principles, Protocols and Applications" was published from Auerbach Publishers (Taylor and Francis group), USA. His major areas of research are Wireless Ad hoc Networks, Sensor Networks and Mesh Networks. He has to his credit more than 45 research publications in National/International Journals and Conferences. $\mathrm{He}$ is recipient of ISTE National Award instituted by U.P. Government for Outstanding Work done in specific areas in Engineering and Technology for the year 2008. He is also recipient of Jindal Merit Scholarship from 1992-1995. ISTE has identified him as a Visiting Professor for the year 2007 in the field of Computer Science. His name was listed in Marquis Who's Who in the World, America in the year 2010 